\title{
Sheridan "arreglado" para la escena española: La escuela de la murmuración, de Rafael Galves Amandi (1861)
}

\author{
Rafael Galves Amandi's La escuela de la murmuración (1861): A Spanish \\ theatrical adaptation of Sheridan's The School for Scandal
}

\section{Purificación Ribes Traver}

Universitat de València. purificacion.ribes@uv.es

Recibido: 14/07/2017. Aceptado: 14/11/2017

Resumen: La comedia más notable de Richard Brinsley Sheridan, The School for Scandal, se estrenó en Londres en 1777 y, debido a su enorme popularidad, se editó, representó y tradujo a diferentes lenguas a lo largo del siglo XIX. Rafael Galves, consciente de las notables diferencias de carácter ideológico, cultural y estilístico entre el teatro inglés y el español, realizó una profunda adaptación de la obra al verterla al castellano en 1861. Este artículo tiene como objetivo analizar de qué forma los rasgos estructurales, temáticos y estilísticos de su versión libre de la comedia se adecuaron a la sensibilidad y el gusto de los espectadores españoles de mediados del siglo XIX.

Palabras clave: Sheridan; School for Scandal; Galves; adaptación española; 1861.

\begin{abstract}
Richard Brinsley Sheridan's most outstanding comedy, The School for Scandal, was premièred in London in 1777. It became an instant success and was repeatedly staged, edited and translated into a variety of languages. Its popularity with audiences did not wane over the course of the nineteenth century, but remained high. In 1861 Rafael Galves completed a Spanish version of the play. Aware of the comedy's specific ideological, cultural and stylistic features, he thoroughly adapted it to the Spanish stage. It is the aim of this article to assess to what extent the structural, thematic and stylistic features of his free version catered to the taste and sensibility of its target audience.
\end{abstract}

Keywords: Sheridan; School for Scandal; Galves; Spanish adaptation; 1861.

》) Ribes Traver, Purificación. 2017. “Sheridan 'arreglado' para la escena española: La escuela de la murmuración, de Rafael Galves Amandi (1861)". Quaderns de Filologia: Estudis Literaris 22: 189-216. doi: 10.7203/qfed.22.11259 



\section{1. ¿Por qué The School for Scandal?}

E1 1 de febrero de 1861 se representaba en el Teatro Príncipe de Madrid la comedia La escuela de la murmuración, adaptación realizada por Rafael Galves Amandi de The School for Scandal, estrenada por su autor, Richard Brinsley Sheridan, en el teatro Drury Lane de Londres el 8 de mayo de 1777. La obra de Sheridan había alcanzado un éxito sin precedentes, que no se limitó al último cuarto del siglo XVIII, momento de esplendor del género al que pertenece ${ }^{1}$, sino que se perpetuó a lo largo del siglo XIX, de modo que, cuando Galves acometió su "arreglo" para la escena española, la obra gozaba de inmejorable salud, como ponen de relieve las incesantes reposiciones de la misma en escenarios ingleses y el buen número de ediciones y traducciones de la obra a otras lenguas.

Un siglo después de su estreno, con motivo de su representación en el Haymarket Theatre de Londres, la crítica se refería a ella como "the greatest dramatic work of the eighteenth century" (The Academy, 1875: $128)^{2}$, y se llegaba a exclamar, a propósito de su excelencia: "No one can be weary of it till it is known by heart". The School for Scandal, en definitiva, había adquirido estatus de obra clásica, y así era percibida, no solo en Inglaterra, sino también en los países circundantes, entre los que se contaba España. Esta convicción es, sin duda, la que lleva a Rafael Galves, autor de su adaptación al castellano, a justificar su "refundición y arreglo a la escena española". Así, en la nota introductoria a su versión escénica afirma sin paliativos: "Todos los hombres amantes de la literatura dramática conocen y acatan el nombre de Sheridan", y especifica que, de sus obras, la que ofrece ante su público es "la mejor

\footnotetext{
${ }^{1}$ Coincidimos con la observación que Leonard Leff hace a propósito de la coexistencia, en la comedia de Sheridan, de rasgos procedentes, tanto de la comedia de ingenio inglesa, como de su sucesora, la comedia sentimental. Dice Leff: "under the surface of Sheridan's chastened comedy of manners lie characters and actions distinctly sentimental" (1986: 65). Y, aunque el propio Sheridan ridiculizara la comedia sentimental, a la que, en el Prólogo a The Rivals, se refería a ella como "the goddess of the woeful countenance" (vv. 22-23), sin embargo, es innegable que, como afirma Leff, "[Sheridan] delicately mocked the excesses of sentimentalism while remaining its sustainer" (1986: 68). ${ }^{2}$ Que esta percepción no era errónea lo ha puesto de manifiesto la crítica posterior, como puede apreciarse en la valoración que Cecil Price hace de la comedia cuando dice: "The School for Scandal is without dispute the most brilliant comedy written in the eighteenth century, and one of the most successful ever produced on the English stage" (1971: 13).
} 
de tan esclarecido ingenio" (1861: 3). Consciente de la dificultad de la empresa, se refiere a ella como "osadía, y grande" (3), por lo que pide una actitud benevolente a potenciales lectores y espectadores, tanto ingleses como españoles: "disimulen la nación inglesa un desacato, y el público español, una ligereza, y con esto solo se dará [el refundidor] por satisfecho" (4).

En su nota introductoria, Galves incide en las notables diferencias entre los destinatarios de la obra original y los de su adaptación: "traducir la obra [de Sheridan] no hubiera sido fácil: el carácter de la nación inglesa por un lado, y el de la española por otro, hacían casi imposible este trabajo" (4), razón por la cual, opta conscientemente por adaptarla libremente, con todos los riesgos que ello entraña, y por lo que, hábilmente, pide disculpas: "los defectos del arreglo son del refundidor o imitador; las bellezas, si alguna he conservado, del autor" (4).

Que Galves realizó un trabajo digno de encomio, y logró su objetivo de adaptar la esencia de la obra inglesa al contexto español, lo ponen de relieve los comentarios de los críticos a su versión escénica, quienes señalan su capacidad para resultar -como ocurriera con Sheridan- a un tiempo, moralizante y entretenida ${ }^{3}$.

Así, La Correspondencia de España (1861: 3) decía al día siguiente de su estreno: "anoche se ha estrenado en el teatro del Príncipe la comedia en cinco actos titulada La escuela de la murmuración, imitación de la que escribió con el mismo título el célebre Sheridan. Esta obra encierra un bello pensamiento moral y entretiene agradablemente al espectador". Este era el doble objetivo, no solo de la comedia alegre ("laughing comedy") inglesa ${ }^{4}$, cuyos máximos exponentes fueron Sheridan y Goldsmith en el último cuarto del siglo XVIII, sino también del proyecto de reforma teatral publicado en 1860 por M. Alaminos y $\mathrm{H}$. Sánchez de la Plaza con el título El teatro español bajo su verdadero punto de vista, donde se incide en la importancia del valor educativo

\footnotetext{
${ }^{3}$ Katherine Worth resume a la perfección la esencia de The School for Scandal cuando la define como "a sympathetic and truthful as well as brilliantly amusing comment on life's ironies and absurdities" (1992: 157).

${ }^{4}$ En el Prólogo a The Rivals, Sheridan señala el humor amable como rasgo esencial de este tipo de comedias: "Look on this form [laughing comedy], where humour, quaint and fly, / Dimples the cheek and points the beaming eye; [...] While her light mask or covers satire's strokes / Or hides the conscious blush her wit provokes" (Vv. 7-12), que Loftis describe como "benign comedies with a satirical bite" (1976: 9).
} 
del teatro, al tiempo que se destaca la particular inclinación del talante español a la literatura "dulce, [...] seductora y de sentimiento" (19). En el mismo texto se reprueba la práctica extendida de representar obras transpirenaicas de moda que, por su tono sombrío y sus "nauseabundos absurdos" (13), atentan contra los principios básicos del teatro español. Curiosamente, ésta era la misma percepción que, en esa década, se tenía en suelo inglés de la invasión perpetrada en sus escenarios por el género melodramático francés. Así, Frederick Wedmore, en su reseña a la reposición de The School for Scandal, de 1882, contraponía los méritos de esta obra a los deleznables excesos de los folletines franceses, que habían estado omnipresentes en los teatros ingleses veinte años antes: "Even in the days which were almost the darkest for the English theatre -the days in which pure sensationalism was rampant, some twenty years ago- The School for Scandal was not wholly laid on the shelf [...] when it was considered desirable that at any particular playhouse some tradition of stage dignity should be maintained" (109).

Esta dignidad escénica es precisamente la que Galves intentaría destacar en su adaptación, para lo cual no dudó en corregir las deficiencias de carácter estructural que encontró en el original inglés, al tiempo que dotó a sus personajes de una mayor coherencia, y aclimató el contenido y el tono de la "escuela del escándalo" a la sensibilidad del suelo patrio.

\section{Estructura dramática}

Puesto que la coherencia estructural de la comedia está indisolublemente unida a la caracterización de los personajes, los cambios que Galves estimó necesarios en el primer aspecto conllevaron sustanciales modificaciones en el segundo. Lo cierto es que, a pesar de la enorme popularidad de que gozó The School for Scandal, especialmente por la brillantez de sus intercambios lingüísticos ${ }^{5}$ y la comicidad de algunas de sus escenas ${ }^{6}$, sin embargo los críticos con frecuencia aludieron a la falta de homogeneidad del conjunto, así como a la deficiente conexión

\footnotetext{
${ }^{5}$ Jack Durant (1995:111) sintetiza admirablemente las valiosas cualidades de su lenguaje: "To assess Sheridan as a playwright of language is certainly to admire the energy and sparkle of his dialogue and to marvel at his amazing mind for sound, rhythm, and verbal nuance".

${ }^{6}$ Particularmente célebre sería la escena del biombo, de la que The Morning Chronicle dijo: "There hardly ever was a better dramatic situation than that which occurs in the
} 
entre las partes que la integran ${ }^{7}$. También fue frecuente la queja relativa a la excesiva lentitud y complejidad de la primera escena, en la que se introduce una amplia galería de personajes y de hilos argumentales, no siempre claramente definidos. Por último, la crítica a menudo apuntó al carácter aparentemente improvisado del desenlace, intuyendo que su autor no le dedicó el tiempo que habría sido conveniente para un final más trabado.

Galves, al acometer su adaptación, realizó un concienzudo trabajo, como señalaron diversos críticos, tras su estreno ${ }^{8}$, que dio como resultado una comedia más ágil ${ }^{9}$, donde se evitaron las redundancias y las incoherencias, donde el avance de la acción estuvo claramente motivado, y donde el final se ajustó de forma más clara al principio de justicia poética.

En su afán por dotar a la obra de una mayor coherencia, realizó diversas transposiciones escénicas, de modo que cada acto se desarrollara en una única ubicación. De este modo, el primer acto se desarrolla en la "Academia de la Maledicencia", presidida por Dña. Virtudes (Lady Sneerwell en Sheridan), y a la que acuden su ayudante Juan de Mata (Snake), su amiga Cándida Pedrero (Mrs. Candour); D. Benigno Gabarro (Crabtree), su sobrino Serafín Machuca (Sir Benjamin Backbite), poeta epigramático; Pura (Lady Teazle), joven esposa de D. Venancio Moraleja; María, pupila de este último, enamorada de Carlos de Sotomayor (Charles Surface), y Modesto (Joseph Surface), hermano de Carlos, que, junto a Dña. Virtudes y Juan de Mata, intentará arruinar su reputación, con el objeto de conseguir la dote de María y dejar el camino libre a Dña. Virtudes, secretamente enamorada de Carlos.

El segundo acto tiene lugar en la casa de los "Moraleja" (Mr. \& Mrs. Teazle), en la que viven Pura, D. Venancio Moraleja, y su pupila María.

fourth act" (9.5.1777), y James Boaden (1825: ix), "I look upon the invention of the screen-scene in the School for Scandal as without a parallel in the drama".

${ }^{7}$ En palabras de John Loftis (1976: 6), "[Sheridan's] strengths relate to his concentration on isolated scenes or groups of scenes rather than on continuity".

${ }^{8}$ Decía La Iberia al día siguiente del estreno: "Arreglos como La escuela de la murmuración, suponen en quien los hace mucha conciencia literaria y no poco estudio, y esto ha llegado casi a ser una virtud en los tiempos que alcanzamos" (3.2.1861: 3).

9 Juan de la Rosa decía lo siguiente a este respecto: "digno de consideración es con efecto el trabajo del señor Gálvez para reducir a cinco los numerosos cuadros de que consta la comedia" (La Iberia, 10.2.1861: 3). 
Carlos con frecuencia ronda la casa para comunicarse con su amada, un comportamiento que es erróneamente interpretado por D. Venancio, quien piensa que los escritos anónimos dirigidos a su esposa (y enviados por Dña. Virtudes y colaboradores) proceden de Carlos. Pura, con seguridad y donaire, le demuestra lo infundado de sus celos y la falsedad de las "pruebas" inculpatorias.

D. Venancio recomienda a su pupila que se olvide de Carlos, cuya fama de manirroto va en aumento, y ponga sus ojos en Modesto, supuesto modelo de integridad y virtud.

D. Andrés de Sotomayor, tío de Carlos y Modesto, llega oportunamente de las Indias con la intención de sondear la verdadera naturaleza de sus sobrinos, antes de repartirles su fortuna. Decide que lo hará bajo una identidad falsa, la del prestamista Zacarías Vellón, en el caso de su arruinado sobrino Carlos, y como el necesitado pariente D. Luis de Saavedra, en el caso del solvente Modesto.

El tercer acto se desarrolla en casa de Carlos de Sotomayor (Charles Surface).

El secretario y ayuda de cámara de Carlos, Quiñones, reflexiona sobre el cambio de conducta de Carlos, que, desde que se ha enamorado de María, rara vez trasnocha.

Acuden a su casa el judío D. Lesmes, con quien Carlos está endeudado, y su nuevo prestamista, D. Zacarías Vellón (D. Andrés), quien le pide una garantía por el dinero prestado. A falta de otra cosa, Carlos le entrega la galería de retratos de sus antepasados, con la excepción del de su tío Andrés, por el que siente gran afecto y agradecimiento, y los de sus padres, a los que apenas conoció. A continuación, le pide un anticipo del monto acordado, para socorrer a un primo suyo, padre de cuatro hijos, que se encuentra en gran necesidad. D. Andrés reconoce la generosidad y buenos sentimientos de su sobrino.

El cuarto acto tiene lugar en casa de Modesto de Sotomayor (Joseph Surface).

D. Andrés acude a casa de Modesto bajo la identidad de Luis de Saavedra, ese primo necesitado de urgente socorro. Modesto, con exagerada cortesía y aparente pesar, le comunica la imposibilidad de socorrerlo, amparándose en su ruinosa situación, resultado de haber ayudado a su manirroto hermano. Preguntado por la generosidad de su tío, afirma no haber recibido de él más que insignificantes regalos, y le invita a abandonar su casa. Tras esta escena, D. Andrés no alberga ninguna duda 
sobre el egoísmo y falsedad de Modesto, a quien su amigo D. Venancio considera un dechado de virtud.

La hipocresía de Modesto se muestra de forma impactante en la siguiente escena, en la que intenta seducir a la mujer de D. Venancio cuando ésta, ingenua, acude a pedirle ayuda para desterrar los celos infundados de su marido. La llegada inesperada de D. Venancio, que también acude a pedir consejo a Modesto, salvará la situación, al tiempo que pone en peligro la reputación de Pura, pues ésta tendrá que esconderse en el dormitorio de Modesto. A la casa acudirá también Carlos, ante lo cual, D. Venancio pedirá a Modesto que sondee las intenciones de su hermano, mientras él escucha la conversación, sin ser visto. Al intentar esconderse en el cuarto de Modesto, D. Venancio descubre que está ocupado por una mujer, y se oculta tras un biombo ${ }^{10}$. La conversación entre los dos hermanos no seguirá los derroteros que Modesto hubiera querido, pues Carlos, que conoce su verdadera naturaleza, le recuerda que sabe que es un mujeriego y un hipócrita, y le traslada los últimos rumores que circulan sobre él a propósito de sus insinuaciones simultáneas a Dña. Virtudes, Pura y María. De la segunda, clarifica que todos saben que ella no lo toma en serio, y de la última, que a nadie se le esconde su interés exclusivo en la dote de la joven. D. Venancio, descubierto el error en que se encontraba, abandonará el biombo y reconocerá que había juzgado equivocadamente a Carlos, y, a pesar de la oposición de Modesto, que finge querer proteger la identidad de la tímida "costurera" oculta en su cuarto, D. Venancio, celoso, averiguará de quién se trata, y quedará estupefacto al reconocer a su mujer, quien, desolada, insistirá en su inocencia.

El quinto acto se desarrolla en casa de Dña. Pura y D. Venancio Moraleja.

Atraídos por el escándalo, y ávidos de noticias, los asiduos del Círculo de la Maledicencia invadirán la casa de D. Venancio. Acudirá primero Cándida Pedrero, con la noble intención de "consolar" a Pura. Seguirán Dña. Virtudes, D. Benigno Gabarro y su sobrino, Serafín Machuca, impacientes por conocer el estado en que se encuentra D. Venancio, tras su supuesto duelo con el "amante" de Pura, cuya identidad

\footnotetext{
${ }^{10}$ Nótese que en la versión inglesa, donde la escena tiene un tono próximo a la farsa, Sir Peter Teazle se esconde en la habitación, mientras Lady Teazle lo hace tras el biombo. De este modo, cuando Charles derriba impulsivamente el biombo, la dama queda en evidencia, ante la sorpresa de su marido, y la carcajada del público.
} 
no tienen clara, pues, tan pronto apuntan a Modesto como a Carlos. Dejándose llevar por su fantasía, toman a D. Andrés por el médico que asiste a D. Venancio en su última hora. Concluye la escena con la súbita aparición del "moribundo", cuya excelente salud destaca D. Andrés, antes de invitarles a abandonar la casa.

Los sobrinos de D. Andrés, avisados por Carrascosa de que su tío, al que no han visto en dieciséis años, se encuentra en casa de D. Venancio, acuden a su encuentro. Ante su sorpresa, Modesto descubre al primo necesitado al que se negó a auxiliar, y Carlos, al prestamista que se quedó con los cuadros de la familia.

Juan de Mata, antiguo colaborador de Dña. Virtudes, confirma, para completa tranquilidad de D. Venancio, que las cartas recibidas por su esposa, procedentes de un supuesto admirador, eran falsas. D. Venancio le promete a Pura que nunca más se dejará llevar por los celos, y esta, escarmentada, que no volverá a poner un pie en la "escuela del escándalo".

D. Andrés concluye la escena constituyendo un simbólico tribunal, del que se erige en juez, para administrar justicia. A su sobrino Modesto lo condena, desheredándolo, por ingrato, falso, mujeriego y mal amigo. Acto seguido lo expulsa de la casa de D. Venancio.

A su sobrino Carlos le agradece la generosidad que le mostró cuando se encontraba necesitado, y el cariño que puso de relieve al no desprenderse del cuadro de su tío, a pesar de la importante suma que le ofreció para ponerlo a prueba. Como premio, y persuadido de que su afecto por María le ha hecho cambiar de costumbres, le promete el dinero suficiente para saldar sus deudas y emprender un negocio que le permita vivir con dignidad.

Recuperada la propiedad de su casa, Carlos insinúa que estará muy vacía, a menos que, como apunta Pura, María vaya a ocuparla, como su esposa, ante lo cual, D. Andrés le concede un plazo de seis meses para lograrlo.

El final de la comedia, fiel al principio de justicia poética, castiga la maledicencia, la falsedad y el engaño, al tiempo que premia el comportamiento sincero, generoso y afectuoso.

Este final, sin embargo, no se obtiene sin antes realizar una labor de criba, donde comportamientos absurdos presentes en la comedia de Sheridan son acertadamente corregidos. Así, por ejemplo, en la primera escena se suprime la justificación que esgrime María para explicar su 
presencia en casa de Mrs. Sneerwell, a la que acude huyendo del asedio de su pretendiente, Sir Benjamin Backbite, personaje de cuyo interés por María nada se sabía y nada se sabe después, especialmente si tenemos en cuenta que esta cotizada pupila dispone ya de dos pretendientes con más posibilidades de obtener su mano: Charles Surface, el calavera que está enamorado de ella, y su hermano Joseph, el hipócrita con fama de íntegro que sólo persigue su dinero.

También suprime Galves la ridícula conducta de Joseph, que, para ganar la simpatía de Lady Teazle, esposa del tutor de María, a cuya mano aspira, torpemente flirtea con ella, aun no sintiéndose atraído por sus encantos, con lo que consigue entorpecer sus propias pretensiones, al despertar los celos de Lady Teazle, primero, y los de su marido, después.

Suprime, igualmente, la inexplicable reacción de Sir Peter en casa de Joseph, tras descubrir, sin ser visto, la verdadera naturaleza de su anfitrión y sus intenciones nada inocentes respecto a su esposa. Aunque Sir Peter escucha, oculto, la conversación en que Charles alude a las miradas insinuantes entre Joseph y Lady Teazle, y a las frecuentes visitas de ésta a su casa, sin embargo, su motivación para descubrir la identidad de la "French milliner" escondida en su casa, no son los celos, sino una curiosidad infantiloide. En el colmo de los ridículos, Sir Peter titubea porque teme que esta acción pueda molestar a su "amigo" Joseph: "No, Joseph will never forgive me!" (IV.iii. 440).

Las absurdas escenas en que Sir Peter y Lady Teazle discuten por ver quién tiene la última palabra, y los comentarios del marido afirmando que su esposa está encantadora cuando se enfada ${ }^{11}$, son suprimidas, porque restan fuerza a sus diferencias, y relevancia a la motivación que Galves destaca de entre las demás, los celos que despiertan en un marido mayor las cartas que su joven esposa recibe de anónimos admiradores.

La ternura que Lady Teazle experimenta cuando, oculta tras el biombo, escucha a su marido pedir consejo a Sir Joseph respecto a sus planes para incrementar la asignación económica de su derrochadora esposa, es suprimida en la adaptación de Galves, ya que en ella ni es necesario

\footnotetext{
${ }^{11}$ Galves suprimirá absurdas exclamaciones de Sir Peter, inconcebibles en un contexto español, como: "With what a charming air she contradicts everything I say, and how pleasingly she shows her contempt of my authority!" (II.1.121-122).
} 
que Pura se desengañe respecto a Modesto, pues este no es su "Platonic Cicisbeo"12, ni Pura aspira a tener independencia económica de su marido.

Finalmente, Galves suprime de la última escena, por innecesaria, el momento en que María, que ha suspirado por Charles durante toda la representación, lo rechaza, en un primer momento, por unas cartas supuestamente falsas de las que en la obra de Sheridan nadie se acuerda, para, instantes después, aceptarlo como marido. En Galves, esas cartas sencillamente no existen, ya que, en una versión donde la motivación de la conducta de los personajes no se descuida, estos documentos van dirigidos en exclusiva a Pura. Galves suprime esa innecesaria vuelta de tuerca, que no añade interés, tensión ni complejidad al personaje ni a la situación, y, en su lugar, concluye la obra con un final feliz, consecuencia lógica de las acciones precedentes.

\section{Personajes}

Los personajes de la comedia, que en Sheridan aún recuerdan a los de la Comedia de la Restauración, son acomodados al contexto español. Galves naturaliza los tipos cómicos que encuentra en la obra de Sheridan, ya que estos se encuentran fuertemente anclados en la tradición teatral inglesa, y, en buena medida, conservan rasgos de los personajes característicos de la Comedia de Ingenio, floreciente un siglo antes. Así, la joven esposa procedente del campo que, casada con un hombre mayor que ella, descubre el atractivo de la vida londinense, e intenta imitar la conducta de las damas de la alta sociedad, magistralmente expuesto por Margery Pinchwife en The Country Wife (1675), de William Wycherley, se condensa y modera en el personaje de Lady Teazle, que, como Margery, procede de un entorno rural, aunque su lenguaje no conserva la simplicidad sintáctica, ni las incorrecciones gramaticales que denotaban el origen de Margery, sino que, desde el principio, exhibe un envidiable dominio del lenguaje. Como Margery, Lady Teazle se sentirá fuertemente tentada por una vida de lujo y placer a la que no está acostumbrada, aunque, a diferencia de ella, no será infiel a su marido, aunque se sienta atraída por un rival más joven (Joseph Surface).

\footnotetext{
${ }^{12}$ Acompañante habitual de una mujer casada, destinado a entretenerla de manera platónica.
} 
Finalmente, en lugar de aprender a disimular una conducta socialmente reprobable, como hiciera Margery, se reconciliará con su marido, al que prometerá su afecto y dedicación. Este, por su parte, aunque guarda relación con el tipo del marido celoso que en The Country Wife encarna Mr. Pinchwife, sin embargo, se diferencia de él en la nobleza de su carácter, el afecto por su esposa y los deseos de hacerla feliz, hasta el punto de que, al objeto de contentarla, y aunque no aprueba su carácter derrochador, dispone concederle una asignación anual que le otorgue la independencia económica que anhela, y lo hace, sorprendentemente, cuando más motivos tiene para estar celoso de ella. Galves, en la adaptación de la pareja, suprimirá la contraposición campo-ciudad, tan arraigada en la tradición inglesa, y, con ella, el afán del personaje femenino por dilapidar el patrimonio familiar en costosos caprichos.

Pura, aunque más joven que D. Venancio, está familiarizada, como él, con la vida de Madrid, aunque se siente deslumbrada por esa "escuela del chismorreo" a la que acude con asiduidad, y en la que disfruta hablando y oyendo hablar sobre el prójimo. Aunque coqueta y alegre, no es derrochadora ni ligera de cascos, y, a diferencia de Lady Teazle, no se siente atraída por el joven Modesto, a pesar de lo cual, las cartas que recibe de un falso remitente (Carlos), enviadas por Dña. Virtudes desde la mismísima "escuela de la maledicencia”, despertarán los celos de su marido, que no se disiparán hasta que, oculto tras un biombo, conozca la verdad (que Carlos está interesado únicamente en María, la pupila de D. Venancio). Puesto que Pura en ningún momento se siente inclinada a engañar a D. Venancio, la escena de reconciliación de los cónyuges se suprimirá, por innecesaria, si bien se conservará su promesa de alejarse de esa "escuela de la murmuración" que tan gravemente ha comprometido su honra y su sosiego. D. Venancio, en justa correspondencia, prometerá a su joven esposa que nunca, en el futuro, se dejará cegar por los celos.

Otro tipo presente en la comedia de Sheridan, procedente de la Comedia de la Restauración, es el del fop, lechuguino obsesionado por estar al día en la moda, que, carente del don de la elocuencia, se cree gracioso y ocurrente, e incluso hace alarde de sus aptitudes poéticas. Este personaje, con los rasgos suavizados, está desdoblado en dos en The School for Scandal: de una parte, Trip, el criado de Charles, endeudado por imitar las modas y extravagancias de la sociedad elegante, y, de otra parte, Benjamin Backbite, autor de ridículos poemas sobre los te- 
mas más absurdos, que critica sin piedad a propios y extraños, y que se postula como candidato a la mano de la heroína de la comedia, María, reservada, como es habitual, para un personaje con mejores prendas.

Este personaje no es otro que el del libertino reformado por amor, que, en Sheridan, contiene no pocos rasgos de Tom Jones, el protagonista de la novela homónima de Henry Fielding, publicada en 1749. Como el personaje de comedia, Charles aparecerá en su casa, entregado al juego y la bebida, y participando en un simbólico brindis en honor de la mujer. Como él, y sin que sus acciones demuestren convincentemente sus palabras, afirmará su transformación y su deseo de cambiar de vida por amor. Como Tom Jones, Charles se mostrará generoso, y su lenguaje, claro y directo como el suyo, contrastará con el de su hipócrita hermano Joseph, trasunto del Blifil de la novela.

La adaptación de Galves reduce el artificio que dejan entrever, tanto la caracterización de Trip y Benjamin Backbite, como la de los propios hermanos Surface, y, en su lugar, ofrece tipos cómicos más creíbles y humanos, con la ventaja innegable de que, al transformar a Joseph Surface en Modesto de Sotomayor, el público tiene la oportunidad de contemplar ante sus ojos a un hipócrita de carne y hueso.

El criado Trip, que en la versión de Sheridan posee un sorprendente dominio de la jerga de los negocios, se transforma en la adaptación de Galves en Quiñones, un personaje que, además de ayuda de cámara de Carlos, es también su secretario, lo que explica su conocimiento de los entresijos de los negocios jurídicos, si bien no hace un alarde de los mismos comparable al que, de manera sorprendente e innecesaria, realiza Trip. Quiñones, personaje amante de la buena vida, aunque no obsesionado por estar a la moda, recupera de Carlos el dinero que este le adeuda, tras lo cual, desaparece de escena, siendo su función como secretario transferida a un personaje más cabal, Carrascosa (Rowley), que ayudará a Carlos en el bufete de abogado que éste, con ayuda de su tío Andrés, está a punto de abrir. Galves, atento a la "delicadeza y sensibilidad" del espectador español a que aludía Alaminos, no deja cabos sueltos, y aplica el principio de justicia poética incluso a los personajes secundarios. Al mismo tiempo, añade elementos ausentes del original, como el ejercicio de una profesión respetable con que el reformado galán de esta comedia, premiado con la mano de su amada, se despide. Esta adición de Galves evoca el final de la novela Tom Jones, donde el protagonista, casado con Sophia, emprende una actividad económica 
próspera y admirable, que contrasta, como en el caso de Carlos, con su pasado de disipación. Al mismo tiempo, suprime la afirmación directa, que en Sheridan recuerda a la novela, de la capacidad de su amada para lograr, con su ejemplo, la transformación del joven ${ }^{13}$. Galves se inclina por una fórmula indirecta para lograr el mismo objetivo, y lo hace a través de los comentarios de Quiñones, quien, todavía a su servicio, se sorprendía de que su amo hubiera dejado de trasnochar, y, desde que conoció a María, llevara una vida conventual.

El personaje de D. Serafín Machuca, aunque, como Sir Benjamin Backbite, disfruta escribiendo poemas, sin embargo, en ningún momento alcanza el extremo de ridiculez del modelo inglés, que presume, entre otros, de los versos escritos a propósito de la pluma de un sombrero a la que se prendió fuego. Tampoco persigue de manera obsesiva y absurda a María, $\mathrm{y}$, aunque se le insinúa, rápidamente comprende que no tiene posibilidad de ser correspondido, por lo que, sin alterar su ánimo lo más mínimo, dirige sus requiebros a Cándida Pedrero, quien, emocionada, simula no entenderlo, para, minutos más tarde, aceptar, encantada, que la escolte. Galves, que reproduce con gracia e ironía la conducta de Mrs. Candour, quien murmura "afablemente", no la ignora ni castiga con severidad, sino que le asigna un pretendiente hecho a su medida, $y$, puesto que ya no es joven, confía, como su amiga Dña. Virtudes, en que su boda con el poeta llegue a materializarse. Distinto es el final que Galves asigna a este último personaje, ya que Dña. Virtudes (Mrs Sneerwell), al poseer la lengua más viperina del periódico El EScorpión, e intentar interferir con sus escritos en la felicidad de Carlos, María, Pura y Venancio, es excluida de la escena final de celebración, y confinada, como Modesto, al aislamiento.

De todos los personajes, es éste el que expone de manera más convincente el rechazo a la hipocresía, idea que, en la comedia de Sheridan, se verbaliza constantemente, aunque nunca se llega a exponer con una claridad comparable a la versión de Galves. De todos los momentos en que aparece el personaje, es en la escena del biombo donde más patente

\footnotetext{
${ }^{13}$ Dice el narrador de la novela respecto a la benéfica influencia de Sophia sobre Tom: "Whatever in the nature of Jones had a tendency to vice, has been corrected [...] by his union with the lovely and virtuous Sophia" ([1749]1966: 873). Charles, de manera comparable, exclama al final de la comedia respecto a la transformación que María efectuará en él: "[She] shall be my monitor -my gentle guide-. Ah! can I leave the virtuous path those eyes illumine?" (V.iii.294-296).
} 
queda su verdadera naturaleza. Este personaje, a diferencia de Joseph, no es frío ${ }^{14}$ ni indiferente a las mujeres, por lo que su falsedad queda inmediatamente de relieve.

A diferencia de la comedia de Sheridan, Pura no visita asiduamente a Modesto, ni se siente atraída hacia él, sino que acude a su casa por única vez, oculta tras un velo, para no ser descubierta, y con la intención de encontrar una fórmula con que acallar los celos infundados de su marido, de los que en última instancia son responsables tanto Dña. Virtudes como Modesto. Cuando le anuncian la llegada de una mujer de identidad desconocida, Modesto se emociona, y empieza a pensar en distintas mujeres tanto solteras como casadas, que va descartando a medida que recuerda los obstáculos que pueden dificultar la visita. Así, por ejemplo, rechaza la idea de que se trate de "La Eugenia", porque su madre la vigila, ni de "La Teodora", porque su marido la controla muy de cerca. Cuando por fin sube Pura, y se quita el velo, él le manifiesta de todas las maneras imaginables lo atractiva que le resulta, tanto por el traje "negligé" que lleva puesto, como por esa mirada de "quiéreme o te mato" (IV.ii.p.44). Aunque Pura le dice claramente que no tiene ningún interés en él, y éste parece empezar a controlarse, de repente vuelve a la carga, porque "ya no puede contenerse más" (IV.ii.p.45), ante lo que Pura se espanta, para experimentar una sensación de alivio y sobresalto, cuando, de repente, se anuncia la llegada de D. Venancio. Pura, desconcertada, no sabe qué hacer, pues los celos de su marido irán en aumento si la descubre allí, por lo que acepta ocultarse en el lugar más próximo, el cuarto de Modesto. D. Venancio, en una situación de deliciosa ironía dramática, dice acudir a casa de Modesto, convencido de que la integridad de éste lo hace idóneo para que le confíe sus problemas. Le dice que sospecha que Carlos ronda a su mujer, y le pide consejo. Cuando Carlos, poco después, llega, D. Venancio le pide a Modesto que interrogue a su hermano a este respecto, mientras él escucha sin ser visto. Como el cuarto de Modesto ya está ocupado por la "costurera",

\footnotetext{
${ }^{14}$ Peter Wood, director de la producción de The School for Scandal, de 1990, para el National Theatre, expresaba con claridad esta percepción: "I find The School for Scandal very chilly indeed" (1995: 178), y, al compararla con The Rivals, cuya producción para el National Theatre dirigió en 1983, contraponía el carácter esencialmente artificial y frío de esta comedia, al tono más humano de The Rivals: "There's no question that The School for Scandal is an artificial comedy about an artificial society in an artificial city whereas The Rivals is essentially a human comedy" (1995: 178).
} 
se oculta tras el biombo, desde el que oye cómo Carlos habla con su hermano con total franqueza, le pregunta si la novela que está leyendo es de Pigault-Lebrun, le cuenta que está al corriente de su intimidad con Dña. Virtudes, de que ronda a Pura, aunque ésta no le hace caso, y de que va tras María. Respecto a esta, le dice que se aparte de ella, pues es la única mujer que ama.

Carlos le dice que es un D. Juan Tenorio que tiene engañado a Don Venancio. Modesto, que ve comprometida su situación, finge una conducta distinta de la que su hermano bien conoce, ante lo que este le replica que su actuación supera a la del propio Isidoro Máiquez. Cuando D. Venancio, impaciente por conocer la identidad de la persona que se oculta en el dormitorio de Modesto, le obligue a salir, y descubra que es su propia mujer, exclamará, indignado y resentido: ¡Hipócrita miserable! (IV.ix.p.50)

\section{Tono}

Si bien la maledicencia y la hipocresía son vicios universales, por lo que las obras que los ridiculizan tienen garantizada su pervivencia, sin embargo el contenido y los límites de esa maledicencia poseen marcadas fronteras nacionales, que Galves rápidamente detectó y supo adaptar en su versión. Así, las alusiones que en la obra de Sheridan realizan los "alumnos" de la "escuela de la difamación" a los deslices morales de diferentes personajes -maridos burlados, hijos extra-matrimoniales, bodas realizadas con imperiosa velocidad-son suprimidas o adaptadas, siendo aquellas descripciones burlescas del empeño vano por disimular la edad o las imperfecciones físicas las que, de forma sistemática, se retienen y amplían, adaptando los detalles al nuevo marco cultural.

En general, el contenido de las noticias escandalosas que comentan los miembros de la "escuela de la murmuración" se suavizan o reducen. Así, por ejemplo, la alusión a la fuga de una señora casada -"I was told that Mrs. Gadabout had eloped with Sir Fillagree" (I.i.223-4)- se transforma en un rumor falso, contado en tono gracioso, sobre el supuesto encaprichamiento de una señora con su primo: "Doña María de las Nieves Cerezo está sumamente triste [...][1a] han indispuesto con su marido, diciendo que se abrasaba por un polluelo, primo suyo por añadidura" (I.ii.p.11). La fuga de una menor sencillamente se omite, de modo que Galves no ofrece equivalencia para "They say her [Miss 
Prim's] uncle stopped her last week just as she was stepping into the York Diligence with her dancing-master" (I.i.231). Tampoco la ofrece para la infidelidad de la esposa de "Lord Buffalo", el simbolismo de cuyo nombre no deja lugar a la duda: "Miss Tattle, who was by, affirmed that Lord Buffalo had discovered his lady at a house of no extraordinary fame" (I.i.255-7). La referencia al sinnúmero de jugadores arruinados, tanto en las cartas como los dados, se suprime, de modo que no necesita traducir el simbolismo de los nombres de "Lord Spindle", "Sir Thomas Splint", "Captain Quinze", o "Mr. Nickit".

La alusión indirecta a los embarazos indeseados, que Sheridan formula de forma clara -"A certain widow in the next Street had got rid of her dropsy and recovered her shape in a most surprising manner"(I.i.253-255)-, se reformula de tal modo que el simbolismo de "dropsy" y de "recover her shape" se diluyen: "Una de nuestras amigas [...] fue a curarse de una hidropesía, y es más, lo logró y volvió a Madrid perfectamente buena" (I.vi.p.12). Aquí "curarse" no tiene las mismas connotaciones que "get rid of", ni "volver buena", las de "recover one's shape". También se suprimen las "pressing reasons" que llevaron a Miss Nicely a casarse con su lacayo. Por lo demás, Galves reproduce la diferencia de clase entre Doña Dolores Silvestre y su "groom", pero su matrimonio no se plantea como manera de ocultar un desliz, sino como única opción abierta a una mujer escasamente agraciada y entrada en años. Los comentarios maliciosos que los miembros de la Escuela de Mrs. Sneerwell realizan a propósito del desliz ocurrido a una mujer tan prudente, tan cauta y reservada como Miss Nicely, se sustituyen en la Academia de Dña. Virtudes por alusiones burlescas al aspecto físico de Dña. Dolores Silvestre, de la que no solo se dice que es "alta, fea, vieja y algo hombruna" (I.vi.p.12), sino que se aportan detalles para subrayar esto último. Dice Benigno Gabarro, tan escasamente refinado como Crabtree: "Hay quien dice que se afeita", a lo que D. Serafín Machuca, tan poco sutil como Sir Benjamin Backbite, repone: "Pues bien, esa señora, o más bien, ese cabo de gastadores, se ha enamorado de su groom". Doña Cándida, tan "comprensiva" como Mrs. Candour, se apresura a ofrecer una justificación: "Doña Dolores se habrá hecho cargo de que no se hallaba ya, ni por su edad, ni por sus circunstancias, en el caso de pedir gollerías: y yo encuentro su conducta muy disculpable" (I.vi.p.12).

Las burlas sobre el ridículo intento de Miss Vermilion por disimular su edad mediante la asidua aplicación del colorete, se reproducen, casi 
literalmente, en la versión castellana. Así, cuando Mrs, Candour dice de su aspecto: "She has a charming fresh colour" (II.ii.39), Lady Teazle maliciosamente repone: "Yes, when it is fresh put on" (II.ii.40). Esto da paso a un nuevo comentario aparentemente inocente de Mrs. Candour: "I'll swear her colour is natural -I have seen it come and go" (II. ii.41), que es rápidamente aprovechado por Lady Teazle para añadir con descaro: "I dare swear you have, Ma'am -it goes of a night and comes again in the morning" (II.ii.44-45). Galves no parece haber tenido motivos para modificar sustancialmente este inofensivo diálogo, que vierte del siguiente modo:

[Serafín] Su hermana conserva una tez muy fresca

[Dña. Virtudes] ¿Por las mañanas?

[Pura] Por las mañanas, precisamente no; pero cuando sale del tocador tiene unos colores...

[Dña. Virtudes] Eso consiste en que se ayuda.

[Dña Cándida] Pues no puedo asegurar a ustedes que son naturales, puesto que se van y se vienen.

[Serafín] Justamente, señora: se van con la luz y vuelven con el alba (I.vi.p.13).

Las alusiones jocosas a la verdadera edad de Mrs. Evergreen, que ésta intenta disimular bajo gruesas capas de maquillaje, tampoco se reducen ni modifican. "She's six-and fifty", dice Crabtree, a lo que Mrs. Candour, con la malicia que la caracteriza, repone: "Now positively you wrong her; fifty-two or fifty-three is the utmost -and I don't think she looks more" (II.ii.48-52). Galves, como en el caso anterior, no ve razón para omitir detalle alguno, por lo que el diálogo entre Dña. Virtudes y Serafín discurre por cauces parecidos:

[Dña. Virtudes] ¿Conoce Vd. a sus hijas, Don Serafín?

[Serafín] Oh, mucho. La mayor es una muchacha excelente.

[Pura] ¿Muchacha? Yo creo que no cumplirá los cincuenta.

[Serafín] Vd. perdone, Purita: son cincuenta y tres, pero no los representa (I.vi.p.13).

Particularmente divertidos son los comentarios de los contertulios a propósito de los esfuerzos de Mrs. Pursy por adelgazar. Dice de ella Mrs. Candour: "Her bulk is her misfortune and, when she takes such pains to get rid of it, you ought not to reflect on her" (II.ii.94-95). Este 
comentario lo interpreta Lady Teazle como una invitación a detallar los medios por los que pretende conseguir su objetivo: "I know she almost lives on acids and small whey; laces herself by pulleys, and often, in the noon of summer, you may see her on a little squat pony with her hair plaited up behind like a drummer's, and puffing round the Ring on a full trot" (II.ii.98-102). En la versión de Galves, el "piadoso" intercambio entre Virtudes y Cándida sobre los problemas de Dña. Melchora se hace eco del que mantienen Mrs. Candour y Lady Teazle respecto a Mrs. Pursy. Dice Virtudes: “¿Qué otro defecto puede ponerse a esa señora que no sea su corpulencia?" (I.viii.p.15), a lo que Cándida replica: "Ninguno, y aún ése no lo es, porque ni está en su mano adelgazar ni dejar de tomar sus medidas para lograrlo" (I.viii.p.15). Acto seguido, Pura se apresura a detallar en qué consisten esas medidas, igual de exageradas que las que apunta Lady Teazle, pero más verosímiles en el contexto español: "Todas las tardes anda tres leguas, bebe vinagre, apenas toma otro alimento que suero, y se baña tres veces al día. $\mathrm{Si}$, a pesar de estos cuidados que se toma, pesa aún cerca de dos quintales, la culpa no es suya" (I.viii.p.15).

Cabe señalar aquí, a propósito de la adecuación de la comedia al contexto español, que Galves se deja guiar por los mismos principios que llevaron a Isidoro Máiquez, unos años antes, a trasladar a los géneros teatrales clásicos la esencia popular de los entremeses ${ }^{15}$. Si Máiquez, al

\footnotetext{
${ }^{15}$ Isidoro Máiquez (1768-1820), reconocido como el actor más influyente de finales del siglo XVIII y principios del XIX -se le llegó a conocer como el Garrick de España (Rodríguez Cánovas, 1968: 69)-, fue consciente de que el público español participaba más del espíritu de las comedias del Siglo de Oro, de los entremeses y modernos sainetes, que de las obras de los autores neoclásicos, que invariablemente se oponían a los gustos populares (Serrano, 2003: 1327). Esto, sin embargo, no fue óbice para que compartiera las críticas de estos últimos al efectismo predominante en la interpretación de los actores españoles del momento (Palacios, 1988: 308). Influido por la interpretación trágica de Talma, y cómica de Clauzel, a quienes conoció durante su estancia en París (Revilla, 1845: 30-32), Máiquez trasladó los principios que Hamlet exponía a sus actores -de adecuación de la palabra a la acción, y viceversa- a su interpretación, no solo de los textos trágicos, como el Otelo de Shakespeare, sino también de las comedias de Agustín Moreto o los populares sainetes de sus coetáneos Ramón de la Cruz o González del Castillo. El secreto en todos los casos consistió en conectar con su público mediante una interpretación naturalista y expresiva (Revilla, 1845: 34-35). En esto era heredero, en última instancia, de la tradición que iniciara Lope de Rueda (1520-1565) en sus adaptaciones de la comedia italiana a la escena española (Arróniz, 1969), ya que este último, al suprimir las escenas que consideraba accesorias, introducir en sus obras en-
} 
hacerlo, pretendía contraponer ese enfoque al efectismo predominante en la escena española, Galves realiza algo semejante con todos aquellos elementos presentes en la comedia de Sheridan que, por su elaboración o artificio, pueden resultar ajenos a la tradición española.

Así, por ejemplo, transforma en más claro y popular, el retórico lenguaje que utiliza Joseph para difamar a su hermano. Dice Joseph a propósito de Charles: "Lady Sneerwell, I am very sorry to have put any further confidence in that fellow" (I.i.135). Galves transforma estas palabras en una expresión fresca y directa: [Modesto] "No me fío de ese tunante" (I.iii.p.9).

Del mismo modo, recurre a expresiones propias de la sabiduría popular cuando explica la falsedad de Snake, que en el original comentan Lady Sneerwell y Joseph con un lenguaje más elaborado:

[Sneerwell] And do you think he would betray us?

[Joseph] Nothing more likely: take my word for't Lady Sneerwell, that fellow hasn't virtue enough to be faithful even to his own villainy (I.i.143-145).

Este intercambio es transformado en clave castiza, al tiempo que se justifica la razón por la que Snake se ha traducido como Juan de Mata. Dice Modesto: "Temo que entre los dos me han de desopinar de Don Venancio”, un temor que Dña. Virtudes intenta disipar: “ßBah! No diga usted desatinos: Juan de Mata...". La frase es interrumpida por Modesto, quien la completa: "lo mismo mata al amigo que al enemigo" (III. iii.p.8). Mediante la rima, además, subraya la esencial falsedad de este sinuoso personaje, al que relaciona con términos antitéticos: amigo y enemigo.

Particularmente acertada es la solución que Galves escoge para traducir las palabras con que Mrs. Sneerwell y Maria describen al personaje de Mrs. Candour, antes de que ésta haga su aparición en escena. Dice Mrs. Sneerwell: "Though Mrs. Candour is a little talkative, everybody allows her to be the best-natured and best sort of woman". A esto, Maria, disipando toda posible duda sobre la "bondad" del personaje, replica: "Yes, with a very gross affectation of good nature and benevo-

tremeses donde aparecían tipos reconocibles, y adoptar una prosa ágil, sirvió de referente para el posterior desarrollo de diferentes formas cómicas que han vehiculizado la crítica social a través de un humor castizo y chispeante (Canet, 2003: 444-445). 
lence, she does more mischief than the direct malice of old Crabtree" (I.i.194-195). Este diálogo, donde la opinión de Maria se explicita de forma clara, adopta un tono gracioso y chispeante en las rápidas intervenciones de Doña Virtudes y María, a las que se suma, de manera espontánea, Modesto, para completar la imagen de ese ser "angelical". Dice Doña Virtudes: "De ésta, al menos, no tendrás queja, María: tiene el carácter más angelical...”, a lo que María, repone: “¡Ay, señora! Si Doña Cándida es un ángel...”. Por si los puntos suspensivos no fueran suficientemente elocuentes, Modesto, interrumpiéndola, añade: "Yo me guardaré muy bien de entrar en el Paraíso" (I.v.p.11).

Como en el caso anterior, y dado que las referencias a los ámbitos religioso y militar están omnipresentes en el contexto español del momento ${ }^{16}$, Galves hace un generoso uso de las mismas para ilustrar diversos aspectos de la comedia y sus personajes. Así, por ejemplo, el tono abstracto de las palabras con que Mrs. Sneerwell recuerda a Joseph que entre ambos no es necesario que finja una bondad que no posee - "O lud! You are going to be moral, and forget that you are among friends" (I.i.118-1125)- se traduce en imágenes elocuentes, que ponen de manifiesto su hipocresía: [Doña Virtudes] "No diría más un padre Capellán, señor de Sotomayor, pero debe Vd. recordar que en este momento se halla en el campo de sus aliados" (I.ii.p.9).

Del mismo modo, cuando Quiñones alude a la reciente transformación de Carlos, que ha abandonado su antigua vida de crápula, dice que ya no visita a las hijas de Adán, sino que lleva vida de auténtico cartujo (III.1.p.29).

\footnotetext{
${ }^{16}$ Véase, por ejemplo, las comparaciones utilizadas en febrero de 1861 por el periódico La Discusión (1.2.1861: 4) para animar a los jóvenes a participar en los bailes de Carnaval que se celebraban en el Teatro de Oriente y en el de la Zarzuela:
}

Al baile, pues, id al baile

Que allí la vida se esponja.

Inés, no te hagas la monja;

Juan, no hagas vida de fraile (1.2.1861: 4).

A renglón seguido, y en el apartado relativo a "Santos y Cultos", el periódico relacionaba los correspondientes al día: San Ignacio, obispo y mártir; Santa Brígida, virgen, y San Cecilio, obispo y mártir, y anunciaba el comienzo de prácticas devocionales como "las Cuarenta Horas" en la iglesia de religiosas de Nuestra Señora de las Maravillas. 
Carlos, por su parte, le recuerda a su hermano que él no lleva precisamente vida de anacoreta, a pesar de lo cual ha conseguido engañar a propios y extraños: "¡Y el bueno de D. Venancio que te tiene por un $S$. Antonio!" (IV.ii.p.45).

Este "San Antonio", al que trastornan las faldas, se lamenta del estrecho control que el marido de Dña. Teodora ejerce sobre su mujer, comparándolo de forma elocuente, con un guardia civil (IV.i.p.45).

La intensa actividad descalificadora de los miembros de la "escuela de la murmuración", que en el original se expresa de forma genérica -"They'll allow good qualities to nobody" (II.ii.88-91) - gana en concreción y fuerza al ilustrarlo con una imagen militar: “ $¡ A y$, Dios mío!¡Aquí a nadie se da cuartel! (III.ii.p.30).

En la adaptación de la comedia, Galves en todo momento ofrece un equivalente cultural adecuado al del modelo inglés. Así, D. Andrés no viene, como Sir Oliver, de las Indias Orientales, sino de las Occidentales, y, de acuerdo con esta caracterización, en lugar de "nabob", se referirán a él como "indiano", y los regalos a que alude Modesto, en lugar de té o aves exóticas, serán cigarros y dulces.

En el mismo sentido, la galería de cuadros que, en la casa de Charles, han sido pintados por Kneller, en la de Carlos proceden de la paleta de Velázquez o Carreño. Finalmente, la duda sobre si el arma utilizada en el presunto duelo ha sido la espada o la pistola, desaparece en la versión española, ya que solo la segunda es admisible ${ }^{17}$.

\section{Actualidad temática}

A pesar de las claras diferencias culturales entre Inglaterra y España, tanto en el momento de composición de la comedia, como en el de su adaptación, lo cierto es que la universalidad de los temas que abordan las convirtió en idóneas para su público. En el caso español, la obra se representaba al mismo tiempo que la prensa denunciaba la hipocresía

\footnotetext{
${ }^{17}$ La adaptación de Galves tiene en cuenta, en este caso, que, aunque los duelos clandestinos no habían desaparecido por completo ni en Inglaterra ni en España, sin embargo, en ambos países las espadas habían sido sustituidas por pistolas. Este cambio se realizó de forma progresiva a lo largo del siglo XVIII, de ahí que no sorprenda la presencia de espadas en The School for Scandal (1777), y que resulte lógica su sustitución por pistolas en la adaptación española de 1861. El tono jocoso de la alusión al duelo se hace eco, por otra parte, de su evolución, ya que, como apunta Truman (1884: 30-39), el desenlace trágico de estos lances cada vez fue más excepcional en Europa.
} 
generalizada en esa situación de difícil equilibrio que fueron los años de la Unión Liberal (1858-1863). Así, se realizaban constantes alusiones despectivas a los resellados, y a las conciencias adormecidas. Decía, por ejemplo, La Iberia (3.2.1861: 3):

Cuando el sol de la unión ya no caliente, A otro partido emigrará la gente;

Pues para muchos la moderna ciencia,

Consiste en prescindir de la conciencia.

Del mismo modo, se denunciaba la hipocresía de aquellos neo-católicos que, a semejanza de Joseph/Modesto, criticaban el libertinaje ajeno, ignorando el propio: "Los neos se han abrogado el derecho de dar a sus semejantes la gloria o el infierno, de manera que, para salvarse, no hay como hacerse amigo de ellos y tenerles contentos" (3.2.1861: 3). Y concluía: "En siendo uno hipócrita, ya tiene, según sus doctrinas, ganado el cielo". El reverso de esta actitud, que en la comedia representa el personaje de Charles/Carlos, también encontraba referente en la sociedad del momento, como ponen de manifiesto los elogios de los liberales a "la parte sana y noble del pueblo, [para quienes] la fijeza de principios y la lealtad de convicciones no pasan desapercibidas" ( $L a$ Iberia, 10.2.1861: 3).

También eran objeto de atención por parte de la prensa las actividades lúdicas y los bailes que tenían lugar en las casas principales, así como las crónicas de sociedad en que se alababan de forma desproporcionada los encantos de las damas que en ellas deslumbraban. No resulta difícil encontrar un paralelismo entre las críticas de que son objeto diferentes personajes de La escuela de la murmuración que fingen una belleza y juventud que no poseen, y los comentarios acerados de algunos críticos de la prensa madrileña de mediados del siglo XIX sobre el mismo tema. Así, en La Iberia del 3 de febrero de 1861(3) se leía lo siguiente:

Las gacetillas de algunos periódicos se encargan de abrirnos a los profanos esos mundos llenos de luz y de armonía, en los que, según parece, no habita una sola mujer fea [...] Es posible que haya entre ellas alguna, que burlándose de sí misma y del que tan sin piedad la adula, se ponga a recitar estos versos de Argensola ${ }^{18}$ :

\footnotetext{
${ }^{18}$ Se trata de Lupercio Leonardo de Argensola (Barbastro 1559-Nápoles 1613).
} 
Yo os quiero conceder don Juan, primero, Que ese blanco y carmín de doña Elvira, No tiene de ella más, si bien se mira, Que el haberle costado su dinero.

La universalidad de los temas abordados que, como señalaba Juan de la Rosa (10.2.1861: 3), "serán siempre de actualidad, por más que los vicios y las nobles cualidades de la sociedad que en ella se retratan adquieran distintas formas, según los diversos pueblos donde se represente", convirtió a The School for Scandal en una obra sobre la que Wedmore (1882: 109) llegaba a afirmar: "there is no piece which can be seen often with greater advantage or with more continuous delight".

\section{Puesta en escena}

Ese deleite, naturalmente, procedía de la acertada conjunción de un tema atractivo y unos diálogos y situaciones ingeniosos, y su éxito estuvo estrechamente ligado a las capacidades de los distintos actores para representar una obra que, por el elevado número de personajes principales, constituye un verdadero reto para cualquier compañía. Así lo percibió su autor, ya en 1777, cuando, siendo gerente del teatro, diseñó a los personajes a la medida de los actores de que disponía en Drury Lane $^{19}$, hasta el punto de que el reducido desarrollo del personaje de Maria no obedezca a otra razón que a la indisposición de la actriz que inicialmente debía interpretar el pape ${ }^{20}$.

Que Sheridan logró plenamente su objetivo lo pone de relieve la unanimidad con que la crítica alabó la interpretación de toda la compañía, hasta el punto de que, en reposiciones ulteriores, las alusiones a los actores que inicialmente interpretaron los distintos papeles fue una

\footnotetext{
${ }^{19}$ En su primera temporada, que se extendió desde el 8 de mayo a principios de junio de 1777, John Palmer interpretó el papel del hipócrita Joseph Surface; William Smith el del espontáneo y generoso Charles Surface; Thomas King el de Sir Peter Teazle, y Mrs. Abington el de su joven esposa, Mrs. Teazle.

${ }^{20} \mathrm{Al}$ encontrarse Mary Robinson embarazada, Sheridan hubo que adaptar el papel para Priscilla Hopkins, hija del apuntador, cuyas dotes interpretativas eran, al parecer, escasas. De ahí que, como sugiere Maybank (2008: 185), "Her limited talents may be the reason why Sheridan did not write full lovers' parts for Charles and Maria”.
} 
constante $^{21}$. En el caso de la adaptación realizada por Galves para la escena española, lo expuesto en las páginas precedentes pone de manifiesto que estuvo a la altura de su modelo y supo adaptarlo con acierto a las características de la escena española. Si su éxito no fue tan arrollador como el que obtuvo Sheridan en 1777, probablemente se deba a la misma razón por la que numerosas representaciones de The School for Scandal a lo largo de los siglos XVIII y XIX no alcanzaron el nivel de la primera: la dificultad de contar con un elenco de actores de calidad comparable ${ }^{22}$.

Tal vez si la versión de Galves se hubiera representado doce años antes, La escuela de la murmuración habría tenido en Madrid todo el eco que se merecía, pues fue entonces cuando el Teatro del Príncipe -donde se estrenaría la comedia - fue elevado a la categoría de Teatro Español. De esa época dice Luis García Martín en su Manual de teatros y espectáculos públicos (1860: 47) que fue "la más lucida que hemos conocido para este teatro", y explica que "se pusieron obras con todo lujo y propiedad, interpretándose admirablemente" (47). El problema residió, sin embargo, en que, como señala García, "los rendimientos eran excesivamente inferiores a los gastos, de lo cual se resentía el Erario, y hubo de procederse a disolver la compañía" (47-48), a pesar de lo

\footnotetext{
${ }^{21}$ Así, por ejemplo, James Boaden, en su historia reciente del teatro inglés, decía de John Palmer, el actor que interpretó el papel de Joseph Surface: "that actor's representation of this sentimental hypocrite was as perfect a thing as even King's Lore Ogleby, or Parson's Corbaccio" (1825: 274). En términos similares, se refería a la interpretación realizada por William Smith en el papel de Charles: "He gave the completest idea of a warm, generous, and corageous character", llegando a afirmar: "The Charles of The School for Scandal died with him" (1825: 218). Cecil Price, por su parte, destacaría la perfecta compenetración entre Thomas King y Mrs. Abington en la interpretación del matrimonio Teazle: "Thomas King and Mrs. Abington were noted for their skill in playing up to each other, and were to be brilliantly successful in the rallies between Sir Peter and Lady Teazle" (1971: 9-10). Del primero, afirmaba, "King's bewildered testiness was superb", y, de la segunda, destacaba su capacidad para alcanzar "a subtle mixture of country innocence and fashionable sophistication" (1971: 9-10).

${ }^{22}$ Así, el crítico teatral de The Academy destacaba el excelente elenco de actores con que contó The School for Scandal al ser representada en el Haymarket Theatre en 1875, y anunciaba la obra en los siguientes términos: "A rare opportunity for seeing good acting in good comedy is now before the public at the Haymarket Theatre" (1875: 128). Se trataba de una reposición de The school for Scandal interpretada por "a company of unusual strength", sobre la que añadía: "It is not often nowadays that four players of the mark of Mr. Compton, Mrs. Vezin, and Mr. and Mrs. Chippendale, find themselves together" (1875: 128).
} 
cual, en la edición de 1860 se dice que "La empresa cuenta con obras nuevas de aplaudidos autores" (48).

Una prueba de esta última afirmación la constituye la versión realizada por Galves de The School for Scandal, representada al año siguiente como La escuela de la murmuración, en la que destacó la interpretación de José Delgado, primer actor y director de la compañía, del que El Clamor Público dijo que "desempeñó con inteligencia y esmero el papel de Carlos" (1861: 4), y del que La Iberia (3.2.1861: 3) alabó la "mucha naturalidad y franca ingenuidad" con que había sabido interpretar el papel. En esta reseña se destacó también el trabajo realizado por la señorita Marín, que interpretó el papel de Pura. La reseña aparecida en La Iberia el diez de febrero tuvo también palabras elogiosas para el Sr. Calvo, que interpretó el papel de D. Andrés. Pero, aunque $L a$ Época (1861: 4) afirma que, en su conjunto, "la ejecución fue bastante esmerada", y La Iberia (2.2.1861: 3), que "fue oída con atención y gusto", también lamenta que "no haya alcanzado el éxito que merecía" (10.2.1861: 3), a pesar de haber sido "concienzudamente refundida y arreglada" (3.2.1861: 3).

El crítico, consciente de que "lo mejor es enemigo de lo bueno", lejos de lamentar la ausencia de esa compañía ideal que habría sacado a esta acertada adaptación todo el lustre que se merecía, sin embargo reconoce que "el público celebró muy a menudo los buenos toques en que abunda" (La Iberia, 2.2.1861: 3). Destaca, asimismo, la relevancia del libreto, y concluye felicitando a cuantos han hecho posible la representación: "Reciban dichos actores y el señor Gálvez nuestra enhorabuena" (10.2.1861: 3). A nosotros, cumplido ya el cometido de ofrecer un análisis detallado de los muchos méritos que esta versión posee, sólo nos queda unirnos a la felicitación por tan acertada adaptación de The School for Scandal, que, como en raras ocasiones, supo captar la esencia del original y trasladarla, con toda su ironía y humor, a la escena española de mediados del siglo XIX.

\section{Bibliografía}

1777 (9 de mayo). The Morning Chronicle.

1861 (1 de febrero). La Discusión, p. 4.

1861 (2 de febrero). La Correspondencia de España, p. 3.

1861 (2 de febrero). La Iberia, p. 3.

1861 (3 de febrero). El Clamor Público, p. 4. 
1861 (4 de febrero). La Época, p. 4.

1875 (31 de julio). The School for Scandal at the Haymarket. The Academy, p. 128.

Alaminos, M. \& Sánchez de la Plaza, H. 1860. El teatro español bajo su verdadero punto de vista. Folleto escrito exponiendo su situación actual, abusos de la literatura dramática y deseos de corregirlos. Madrid: Imprenta de D. Francisco del Castillo.

Arróniz, Othón. 1969. La influencia italiana en el nacimiento de la comedia española. Madrid: Gredos.

Boaden, James. 1825. Memoirs of the Life of John Philip Kemble, Esq. Including A History of the Stage, from the Time of Garrick to the Present Period. New York: William Brown.

Canet, José Luis. 2003. Lope de Rueda y el teatro profano. En Huerta Calvo, Javier (coord.) Historia del teatro español I. Madrid: Gredos, 431-475.

De la Rosa González, Juan. 1861 (10 de febrero). Álbum. La Iberia, p. 3

De la Rosa González, Juan. 1861 (3 de febrero). Álbum. La Iberia, p. 3.

Díez Borque, José María (ed.). 1988. Historia del Teatro en España II. Madrid: Taurus.

Durant, Jack D. 1995. Sheridan and Language. En Morwood, James \& Crane, David (ed.). Sheridan Studies. Cambridge: Cambridge University Press, 96-114.

Galves Amandi, Rafael.1861. La escuela de la murmuración, comedia en cinco actos original de Sheridan, refundida y arreglada a la escena espanola. Madrid: Imprenta de José Rodríguez.

García Martín, Luis. 1860. Manual de teatros y espectáculos públicos (2. ed.). Madrid: Imprenta de Cristobal González.

Huerta Calvo, Javier (coord.). 2003. Historia del teatro español I. Madrid: Gredos.

Leff, Leonard J. 1986. Sheridan and Sentimentalism. En Davison, Peter (ed.) Sheridan: Comedies. Houndmills: Macmillan, 59-73.

Loftis, John. 1976. Sheridan and the Drama of Georgian England. Oxford: Basil Blackwell.

Maybank, Diane (ed.). 2008. Richard Brinsley Sheridan. The School for Scandal. Oxford: Oxford University Press.

Morwood, James \& Crane, David (eds.). 1995. Sheridan Studies. Cambridge: Cambridge University Press.

Mutter, R. P. C. (ed.). 1966. Henry Fielding. The History of Tom Jones. Harmondsworth: Penguin.

Ogden, James (ed.). 2014. William Wycherley. The Country Wife. London: Bloomsbury Methuen. 
Palacios, Emilio. 1988. El teatro del siglo XVIII (hasta 1808). En Díez Borque, José María (ed.) Historia del Teatro en España II. Madrid: Taurus, 57336.

Price, Cecil J. L. (ed.). [1971] 1986. Sheridan. School for Scandal. Oxford: Oxford University Press.

Price, Cecil J. L. (ed.). [1968] 1985. Sheridan. The Rivals. Oxford: Oxford University Press.

Revilla, José de la. 1845. Vida artística de Isidoro Máiquez, primer actor de los teatros de Madrid. Madrid: Imprenta de D. Miguel de Burgos.

Rodríguez Cánovas, José. 1968. Isidoro Máiquez. Cartagena: Athena Ediciones.

Serrano, Antonio. 2003. La recepción escénica de los clásicos. En Huerta Calvo, Javier (coord.) Historia del teatro español I. Madrid: Gredos, 13211349.

Truman, Ben C. 1884. Field of Honor. A complete and comprehensive history of dueling in all countries. New York: Fords, Howard and Hulbert.

Wedmore, Frederick. 1882 (11 de febrero). School for Scandal, at the Vaudeville. The Academy, p. 109.

Wood, Peter. 1995. On Producing Sheridan. A Conversation with Peter Wood. En Morwood, James \& Crane, David (ed.) Sheridan Studies. Cambridge: Cambridge University Press, 178-188.

Worth, Katherine. 1992. The School for Scandal. In Sheridan and Goldsmith. Houndmills: Macmillan, 138-157. 